lamines, might be fluctuating hypertensive filling of the atherosclerotic coronary vessels in a usually normotensive or hypertensive person. This may cause the trauma to the arterial wall which sets off changes leading to thrombus formation and cardiac infarction.

Treatment with $\beta$-blocking or hypotensive agents might be used to prevent unnatural rises of blood pressure, level out fluctuations, and thus avoid repeated trauma to the vulnerable vessel wall. Many potential patients are not hypertensive, and a raised blood pressure is therefore not the only reason why this approach should be tried.-I am etc.,

Wanstead Hospital,

ERIC FrankBi

\section{Incidence of Gonorrhoea}

SIR,-Dr. W. H. Hughes and Mr. J. M. Davies (13 November, p. 424) suggest that in Britain and at this time there may not be a reservoir of silent female carriers of gonorrhoea of the size that has been supposed. The annual incidence of gonorrhoea is published by the Chief Medical Officer of the Department of Health using data supplied to him by the special clinics. ${ }^{1}$ It is widely believed that these figures represent a fair sample of the cases occurring and are a high proportion of the total. In 1969 the incidence of new infections among girls of 18-19 years was almost exactly the convenient figure of 400 per 100,000 of the female population of that age and this was by far the highest incidence of any age group.

The investigation of Dr. Hughes and $\mathrm{Mr}$. Davies took place between 11 March and 26 August 1971. It is the study of the prevalence of gonorrhoea among a sample of one third of the new patients at the Samaritan Hospital for Women near the time of their attendance or admission. The prevalence of previously undiscovered infection was $0.30 \%$.

An estimate of the point prevalence in a representative sample of girls of 18-19 years would require at least a knowledge of the mean duration of an infection at this age. On this point there is no statistical evidence available. If to cover this deficiency the assumption is made that all infections discovered and recorded had been present for twelve months, then the estimated point prevalence equals the annual incidence and is $0.40 \%$. Correction factors are required for this rough estimate. An allowance should be made for the probable short-fall in the recording of cases and the failure for a number of possible reasons to make a diagnosis. The result must be multiplied by the appropriate factor. If the assumption that each infection lasted for one year were not in accord with clinical experience, the correction factor required would almost certainly be less than one. The two corrections might therefore be self-balancing.

If the yield of screening programmes should prove to be of the order of, say, $0.5 \%$ then it would require 26,450 examinations using the 1969 figures to increase the discovery of female gonorrhoea in the special clinics by 132 cases or $1 \%$. Many such examinations would be carried out primarily for reasons other than screening. The discovery of gonorrhoea would be a bonus to the patients concerned but a relatively small advantage to the public health.-I am, etc.,

St. Thomas's Hospital,

W. F. FELTON London S.E.1

\section{Department of Health and Social Security. On the the Chief Medical Officer. London, H.M.S.O.}

\section{Need for Asylums}

SIR,-Dr. O. W. S. Fitzgerald (27 November, p. 556) writes of the considerable number of so-called criminals occupying our prisons who are in fact chronic schizophrenics or subnormals, and the difficulty he has in obtaining appropriate care for them when they are discharged from prison.

Having, like Dr. Fitzgerald, moved from a psychiatric hospital into the prison medical service (from which I recently retired), I can endorse his remarks. It was my experience that it was just as difficult to obtain psychiatric treatment or suitable institutional care for these people before committal to prison so that the courts had no choice about disposal.

The mentally ill and the subnormal are a burden to the penal establishments. Efforts are being made to provide suitable care, but there are many difficulties, overcrowding and shortage of suitably trained staff being the biggest. It seems surprising that in our welfare society provision is no longer made for the chronic untreatable mental case whose antisocial behaviour makes him too hot to hold in our "open door" psychiatric hospitals. Such people need long-term care and a prison sentence does not necessarily provide this. Frequently trivial minor offences are committed for which the offenders receive short sentences, and on coming out the whole cycle starts again. One wonders what the cost is in time spent by the police, courts, probation officers, and welfare workers.

It is to be hoped that with the reconsideration of the mental health services an answer will be found, and there will be better liaison between the various agencies involved in the care of these people.-I am, etc.,

Chilham, Kent

FREDA S. REED

\section{Unfair Pressure for Abortion}

SIR,-What is the position of a general practitioner when he disagrees with his patient's request for an abortion? She may decline his offer of social and antenata support and press for abortion, usually on social grounds. Nor are gynaecologists immune from unfair pressure, and there may be more to come. The Medical Practitioners' Union is reported ${ }^{1}$ as having recommended to the Lane committee that the 1967 Abortion Act be amended so that "doctors who refuse to perform abortions should be made to give their reasons in writing." It would seem unlikely that unfair pressure of this type would commend itself to a future Parliament, though such pressure does exist on the other side of the Iron Curtain, where the rule for gynaecologists and their trainees is "abort or get out."

The legal position under the 1967 Abortion Act is quite clear. A practitioner should examine his patient and offer his con- sidered opinion on what he thinks is in her best interest. He may or may not advise a termination, but even in the face of rudeness from the patient, her husband, or her mother there is no legal or moral obligation to offer more than a medical opinion given in good faith. Naturally a Roman Catholic or other doctor with personal reasons making it difficult for him to take part in an abortion consultation should explain the position to his patient, arranging for her to consult a suitable medical colleague, perhaps his partner. Naturally he could not introduce his patient to an advisory agency known to arrange abortion on demand in private. The press and radio must take much of the blame for giving the public the false impression that Parliament in 1967 made it legal for any woman to request and to get an abortion either in the N.H.S. or privately.

Each of us must take up an ethical position, which need not lack compassion for the mother or her baby. I believe that good medical practice is based on kindness, a careful examination, and careful notes. This need not lead to bullying a patient. But, vice versa, a patient should not try to bully or threaten her medical adviser nor should she cross his palm with silver. There are nevertheless occasions when inevitably a patien and her doctor must disagree, but this should always be possible without rancour, and especially since the patient seeking the termination is often distressed, even distraught.I am, etc.

Hugh Cameron McLaren

Birmingham Maternity Hospital,

Queen Elizabeth Medical Centre,

Edgbaston,

1 Daily Telegraph, 24 November 1971.

\section{Australia Antigen in Nigerian Blood Donors} and School Children

SIR,-The high prevalence of Australia antigen ( $\mathrm{Au}(1)$, H.A.A.) in the "normal" population has been reported to be high in tropical areas. ${ }^{12}$ There have also been many reports of the prevalence of $\mathrm{Au}(1)$ in blood donors from several countries. There have, however, been no reports of the prevalence of $\mathrm{Au}(1)$ in blood donors in Nigeria. This information is supplied here. Eight thousand sera obtained from volunteer blood donors, $95 \%$ of whom are men aged between 18-60 years at the University College Hospital, Ibadan, Nigeria, between 1 February and 30 September 1971 were screened by the electroimmuno-osmodiffusion method of Bedarida et $a .^{3}$ The specificity of the detected $\mathrm{Au}(1)$ and its antibody was confirmed by double diffusion using standard reagents

Monthly Prevalence of Au(1) in Nigerian Blood Donors (February-September 1971)

\begin{tabular}{l|r|r|r|c|c}
\hline \multirow{2}{*}{ Month } & \multirow{2}{*}{$\begin{array}{c}\text { Total } \\
\text { No. } \\
\text { Donors }\end{array}$} & \multicolumn{2}{|c|}{$\begin{array}{c}\text { Au(1) } \\
\text { Positive }\end{array}$} & \multicolumn{2}{|c}{$\begin{array}{c}\text { Au(1) } \\
\text { Antibody Positive }\end{array}$} \\
\cline { 3 - 6 } & No. & $\%$ & No. & $\%$ \\
\hline February & 1,001 & 50 & 4.9 & 1 & 0.1 \\
\hline March & 1,044 & 56 & 5.6 & 2 & 0.19 \\
\hline April & 1,121 & 120 & 10.1 & 5 & 0.45 \\
\hline May & 773 & 20 & 3.8 & 1 & 0.13 \\
\hline June & 1,149 & 47 & 4.1 & - & - \\
\hline July & 771 & 29 & 3.9 & 1 & 0.13 \\
\hline August & 998 & 87 & 8.7 & 2 & 0.8 \\
\hline September & 1,143 & 65 & 5.7 & 1 & 0.09 \\
\hline
\end{tabular}


from several laboratories and the method of in Britain and the relatively low exposure Prince. ${ }^{4}$

$484(6.05 \%)$ of the donors were carriers of $\mathrm{Au}(1)$, while $13(0.16 \%)$ had the antibody. There was a monthly variation in the prevalence of $\mathrm{Au}(1)$ antigenaemia, varying from $3.8 \%$ in May to $10.1 \%$ in April (see Table). There was no correlation between the $\mathrm{Au}(1)$ carrier state and ABO blood group or haemoglobin genotype. Au(1) was prevalent in all age groups but commonest in the second and third decades.

Among 423 school children aged between 4 and 20 years who lived in two boarding house in Ibadan $\mathrm{Au}(1)$ was present in $29(6.7 \%)$ and the antibody in $1(0.24 \%)$. There were 208 giŕls and 215 boys in the study population; 11 $(5.3 \%)$ of the girls and $18(8.4 \%)$ of the boys had the antigen. The only student with antibody was a 17-year-old girl.

Details of this study will be published later. We are, etc.

T. I. FRANCIS J. A. SMITH

Departments of Medicine and Pathology,

University College Hospital,

1 Blumberg, B. S., Sutnick, A. I., London, W. T. and Millman, I, New England fournal of

Medicine and Hygiene, 1970, 19, 872. Tropical

Haematologica, 1969, 54, 591 .
Hedarida, Gonara, A., Prince, A. M., Proceedings

Academy of Sciences, 1968, 60, 814 .

\section{Anticonvulsant Osteomalacia}

SIR,-Dr. John Hunter and others (23 October, p. 202) confirmed in children our finding 1 in adult epileptics that calcium metabolism is disturbed by anticonvulsant therapy. Although we agree with them that the most likely cause of this disturbance is altered vitamin $\mathbf{D}$ metabolism in the liver, the evidence which they present goes little further to prove an aetiological relationship between liver enzyme induction and abnormal calcium metabolism than former evidence allowed. Indeed, the inverse correlation which they have shown between serum calcium levels and urinary glucaric acid excretion was to be expected, for they had previously found ${ }^{2}$ a correlation between total daily dose of anticonvulsant drugs and urinary glucaric acid excretion, while we had shown ${ }^{1}$ an inverse correlation between total daily dose and serum calcium levels. It follows, therefore, that glucaric acid excretion should inversely correlate with serum calcium. This does not necessarily imply an aetiological relationship, for if both phenomena are drug induced and dose related a correlation is only to be expected. However, disturbed vitamin D metabolism is the most attractive theory to explain the calcium abnormalities, and has recently been given support by the finding ${ }^{3}$ that phenobarbitone treatment shortens the half-life of tritiated cholecalciferol in man, leading to accumulation of more polar, inactive products in the serum. In addition, the liver microsomes of phenobarbitone-pretreated rats were found in vitro to rapidly convert cholecalciferol to metabolites other than the active metabolite. 25-hydroxycholecalciferol, whereas no significant conversion could be demonstrated in the microsomes of control rats.

The suggestion by Dr. Hunter and others that an increased demand for vitamin D produced in these patients by drug treatment can precipitáte deficiency, given the relatively low dietary intake of the vitamin to sunlight seems to us an eminently reasonable one. We have looked at this point by dividing the patients who were included in our survey ${ }^{1}$ into two groups according to their daily work at the Chalfont Centre. Of the 26 patients who had been working in the farm and farm gardens during the year before our survey only $2(8 \%)$ had low serum calcium levels, whereas of the 102 who had been engaged in indoor work $26(25 \%)$ had abnormal calcium levels. The mean serum calcium $( \pm \mathrm{SE})$ of the former group was $9.48 \pm 0.08 \mathrm{mg} / 100 \mathrm{ml}$ and that of the latte group was $9 \cdot 18 \pm 0 \cdot 04$. The difference between these is significant ( $t$ test, $P<0.005$ ).

While, however, exposure to sunlight is obviously important we consider it important only in so far as it increases the production of vitamin D in patients working outdoors and so makes them less likely to develop a drug-induced deficiency. In the absence of anticonvulsant drug treatment all these patients, whether working indoors or outdoors, would be expected to have an adequate production and intake of the vitamin. It has been stated earlier ${ }^{1}$ that the diet of the patients was considered to be adequate in terms of its vitamin $\mathbf{D}$ content. A subsequent assessment of this has indicated that their daily intake was 75 I.U. on average, which compares favourably with the intake in some areas of Britain. ${ }^{4}-W e$ are, etc.,

Department of Clinical Pharmacology, t. Bartholomew's Hospital, ondon E.C.1

Metabolic Ward, University College Hospital,

Richens, A., and Rowe, D. J. F., British Medical Fournal, 1970, 4.73.

Hunter, J., Maxwell, J. D., Carrella, M., Stewart, D. A. and Williams, R., Lancet, 1971, 1, 572 Avioli, L. V. Clinical Research, 1971, 19, 50 Lumb, G. A., Mawer, E. B., and Stanhury, S. W American fournal of Medicine, 1971, 50,421.

\section{Responsibility of the Scientist}

SIR,-The wise letter from Dr. S. Bradshaw (27 November, p. 557) concerning Sir George Pickering's paper (16 October, $p$. 131) must reflect the opinions of many practitioners and consultants.

It has been disturbing to read the views of many physicians whom we have regarded as eminent, putting "the care of the patient" second to research and investigation. Of course the latter are important to the whole approach but we must keep our priorities right in teaching medicine and nursing to students, otherwise the patient will suffer. -I am, etc.

Leighton Buzzard,

JOHN T. INGRAM

\section{Dichloralphenazone and Breast Milk}

SIR,-The decision to give drugs to nursing mothers is particularly difficult, for not only has the mother to be considered but also the effect the drug may have on the infant if the drug is secreted in breast milk. This note reports our measurement of dichloralphenazone in the blood and milk of a lactating neurotic mother with severe tension by day and insomnia at night. It was to allay these that we began modified narcosis with chlorpromazine and dichloralphenazone.
The patient was a 20-year-old depressed girl with very severe symptoms since the birth of her child five months before her admission. She had wanted to breast-feed the infant and so was encouraged to continue in the belief that this would aid her recovery. She was physically normal. She was given chlorpromazine $100 \mathrm{mg}$ t.d.s. and dichloralphenazone $1,300 \mathrm{mg}$ in the evening. The feeding schedule that she had herself established was unaltered in that the child was breast-fed at 0800,1500 , and 2100 , with a supplementary feed at 1300. Milk, by expression, and blood samples were taken just before each breast feed. The child was weighed before and after feeds to find the weight of milk supplied and from this the volume of milk determined.

In the body dichloralphenazone is reduced to trichlorethylalcohol, which produces the central depressant effect. ${ }^{12}$ The trichlorethanol was measured in samples of breast milk and maternal and infant blood plasma by Mr. D. J. Berry of the Poisons Reference Service, using a sensitive gas chromatographic method. The results are shown in the Table.

TABLE-Trichlorethanol Level $(\mathrm{mg} / 100 \mathrm{ml})$ of Maternal Plasma and Milk after $1,300 \mathrm{mg}$ of dichloralphenazone at 2200

\begin{tabular}{l|l|l|l}
\hline Date & Time & Plasma & Milk \\
\hline 14 July & 1700 & $0 \cdot 15$ & $0 \cdot 12$ \\
& 2100 & $0 \cdot 14$ & $0 \cdot 10$ \\
15 July & 0800 & $0 \cdot 34$ & $0 \cdot 27(0730)$ \\
& 1700 & $0 \cdot 18$ & $0 \cdot 12$ \\
16 July & 2100 & $0 \cdot 13$ & $0 \cdot 08$ \\
& 0800 & $0 \cdot 32$ & $0 \cdot 25(0730)$ \\
& 1700 & $0 \cdot 18$ & $0 \cdot 11$
\end{tabular}

No trichlorethanol was detected in the plasma of the baby at 1800 on 15 July 1971. No chlorpromazine was found in either the patient's milk or serum. The limit of detection of chlorpromazine by this method is $0.05 \mathrm{mg} / 100 \mathrm{ml}$ so that she must have been secreting less than that. We can expect this from the results of other workers. ${ }^{3}$ It will be noticed that the concentration of trichlorethanol in milk reflected that in the plasma, an observation similar to that found with other drugs. The concentration of trichlorethanol in the milk was between 0.6 and 0.8 of that in the plasma a figure higher than that reported for chlorpromazine. ${ }^{3}$

We found the levels obtained at particular times each day corresponded well with each other, and as might be expected the higher concentrations occurred in the morning. The highest concentration in milk was $0.27 \mathrm{mg} / 100 \mathrm{ml}$, which would have resulted in the infant imbibing $40.50 \mathrm{mg}$ of trichlorethanol during its maximum feed $(150 \mathrm{ml})$. The infant's growth, activity, and development during this period were normal except that the infant appeared minimally more drowsy during the early morning. Three months after the drug was stopped the baby is still well.-I am, etc.,

Department of Psychiatry,

J. H. L.ACEY St. George's Hospital,
Tooting, London S.W. 17

1 Butler, T. C.. Fournal of Pharmacology and Exberimental Therabeutics, $1948,92,49$.
Marshall. E. K. and Owens, A. H., Bulletin of Marshall. E. K., and Owens, A. H., Bulletin of
the Fohns Hopkins Hospital. 1954, 95. 1. Blacker, K. H., Weinstein, G. H.. and Ellman,
G. L., American fournal of Psychiarty, 1962/3, 119. 178 .

4 Ayd, F. J., Clinical Medicine, 1964, 71, 1758. 